\title{
TV Escola: reações de professores de Ensino Fundamental ${ }^{*}$
}

\author{
Cláudia Maria de $\operatorname{Lima}^{1}$ \\ Pontifícia Universidade Católica de Campinas
}

\begin{abstract}
As reações de professores a um projeto específico de capacitação docente, desenvolvido pelo Governo do Estado de São Paulo, denominado TV Escola, foram objeto da presente pesquisa. Serviram como sujeitos 33 professores de ensino fundamental de escolas públicas, quase todos do sexo feminino, que participaram do TV Escola em município do Estado e que, em seguida, responderam voluntariamente um questionário com questões abertas e fechadas. Os resultados apontam para uma reação favorável, de modo geral, ao projeto em si. O TV Escola foi encarado principalmente em termos de ganhos futuros para seu trabalho, mas foram mencionados pontos positivos e negativos quanto ao projeto. O projeto foi avaliado como útil e capaz de ajudar a capacitar o professor pela maioria dos sujeitos. Os problemas mencionados referiram-se ao conteúdo dos programas e a aspectos técnico-burocráticos. Concluindo, os professores reagiram positivamente ao projeto TV Escola e indicaram a necessidade de sua continuidade.

Palavras-chave: Capacitação de professores, Ensino à distância, TV e vídeos educativos.
\end{abstract}

\begin{abstract}
TV Escola: reaction of elementary school teachers

The reactions of teachers from a specific project of teachers' staff capacity, developded by Government of São Paulo called TV Escola, are subject from the present resource. Third Three elementary teachers from public schools, most female, answered the open and closed questions spontaneously after partipating on TV Escola in a couty from São Paulo. The resoults indicated pleasent reaction, in general, in the project itself. The TV Escola was mainly viewed by its future winnings for teacher's work. Allthough, some positive and negative aspects about the project were mentioned. It was avaliated by the majority of the subjects useful and capable of helpping to improve the teachers. The problems mentioned, were related to the programms conttents technical-bureaucrat aspects. Finally, the teachers reacted positivelly to TV Escola and indicated the necessity of its pursuit.

Key words: distance education; teachers' capacity; tv and educative tapes.
\end{abstract}

\section{Fundamentação teórica e objetivos}

O quadro da educação brasileira é hoje desanimador: crianças fora da escola, altos índices de analfabetismo e semi-analfabetismo, professores malremunerados e despreparados para enfrentar a realidade da sala de aula (Fu-

* O presente artigo foi apresentado no IV Congresso Paulista sobre Formação de Educadores (1996) em Águas de São Pedro - SP.

1. Este artigo é parte da Dissertação de Mestrado defendida na PUCCAMP com o apoio financeiro da CAPES/ DS.

Endereço para correspondência: Rua Alfaia, 59, Alto da Lapa, CEP 05468-060, São Paulo, SP, Email: rslima@seade.gov.br sari, 1988). O Censo de 1991 revela que mais de $50 \%$ dos alunos repetem a $1^{\text {a }}$ série. Apenas 39\% das crianças brasileiras concluem o $1^{\circ}$ grau e, para isso, repetem em média quatro vezes as várias séries. De acordo com a fonte que menciona estes dados (IBGE, 1994), entre os fatores que mais contribuem para a repetência estão a metodologia, o currículo inadequado e o despreparo dos professores. Enfim, uma situação que não pode continuar em um país que pretende desenvolver-se e proporcionar aos seus habitantes boas condições de vida. O professor é um dos principais envolvidos nessa alarmante 
situação, impondo-se a necessidade de pesquisas e iniciativas que contribuam para a busca de meios a fim de melhorar a preparação desse profissional e, com isso, poder melhorar a qualidade do ensino oferecida. O vídeo e a televisão a serviço da capacitação de professores de ensino fundamental foram escolhidos pela Autora como objeto da presente pesquisa, para estudar como os professores reagem a um projeto dessa natureza. Para tanto, foi selecionado um projeto desenvolvido em 1994, promovido pela Secretaria de Estado da Educação em conjunto com a Fundação Padre Anchieta, especialmente planejado para proporcionar treinamento, informações e o auxílio de que os professores necessitam para melhorar seu desempenho profissional. Tal projeto foi denominado TV Escola.

Este projeto deu à autora a oportunidade necessária para realizar uma pesquisa capaz de concorrer para a melhor compreensão do impacto direto do emprego da TV e do VT na capacitação de professores. Capacitação esta que, se conduzida de modo adequado, pode ser útil para os propósitos de superação dos atuais problemas de reprovação e evasão e para a diminuição de índices preocupantes como o do analfabetismo entre brasileiros com mais de 10 anos, que está em torno de $17,8 \%$, e o de brasileiros com mais de 10 anos sem instrução ou com menos de um ano de escolarização, que chegam a 18,1\% (IBGE, 1994). Parece razoável supor que professores mais bem preparados ensinam melhor, que seus alunos aprendem mais e são mais motivados, reduzindo-se, dessa forma, os dramas evasão, reprovação e analfabetismo, dramas que, sem dúvida, também estão associados a outros fatores e condições, além da preparação docente. Diante desse quadro, a necessidade de atualização de conhecimentos e de práticas docentes cresce extraordinariamente de importância.
Um dos campos de estudos e de teorizações que ocupa cada vez mais espaço na discussão de encontrar soluções para a melhoria do desempenho docente é o da "educação à distância".

Desde meados do século atual, numerosos países vêm desenvolvendo programas de aperfeiçoamento do pessoal docente inteira ou parcialmente por meio de recursos nãoconvencionais, conhecidos como "educação (ou treinamento) à distância". Segundo Jegede (1994), na educação à distância, ao contrário do que ocorre com o modo convencional de ensino face a face, o ensino-aprendizagem ocorre em situação na qual boa parte do ensino ou até mesmo a totalidade deste é conduzida por um professor separado do aprendiz no tempo e no espaço. Além disso, os resultados esperados da aprendizagem são prédeterminados e dependem de um planejamento eficiente e efetivo de materiais que se ajustem às características particulares do aprendiz. Jegede acrescenta que o ensino à distância impõe igualmente a necessidade de uso de mídia selecionada de modo apropriado, para complementar materiais impressos (p. 235).

No Brasil, são escassas, para não dizer inexistentes, as informações sobre programas de educação à distância com o emprego de TV/VT em projetos e iniciativas voltados para o aperfeiçoamento do pessoal docente de ensino fundamental no nosso país (Gait, 1988; Rezende e Fusari, 1990). De modo geral, programas dessa natureza têm sido conduzidos desde a década de 60 sem a preocupação de registros e pesquisas que permitam uma revisão de tudo quanto já se fez no país, nesse domínio. Das várias iniciativas em matéria de emprego da televisão para fins de aperfeiçoamento ou atualização dos professores de ensino fundamental, ocorridas nos país nos últimos 25 anos, infelizmente não existe um registro confiável e minucioso. Apenas um ou outro projeto redundou em publicações que possibilitam a com- 
preensão de sua natureza, de seus objetivos e resultados. Dois desses projetos, de maior envergadura, foram: a) o Curso de Qualificação Profissional, realizado em 1984 pela FUNTEVÊ, destinado a habilitar professores leigos ao exercício do magistério no ciclo básico do ensino fundamental (FUNTEVÊ,1984); b) Projeto Ipê, que foi desenvolvido a partir de 1984 pela CENP em conjunto com a Fundação Padre Anchieta. (Guzzo, 1985).

\section{Avaliação de reação}

Considerando-se que, como foi verificado anteriormente, a avaliação de programas destinados à capacitação docente não é comum no Brasil, ao contrário do que é feito em países como a França, EUA, pensou-se em uma pesquisa que correspondesse a essas necessidades. Wexley e Latham (1991) lembram que, em se tratando primariamente de material/programa que tem por finalidade o ensino-aprendizagem, a efetividade desse programa pode ser avaliada em termos de quatro critérios fundamentais, estabelecidos por Kirkpatrick: a) reação do professor; b) aprendizagem (propriamente dita) do professor; c) comportamento (s) do professor; d) resultados obtidos em classe com alunos.

Eles assinalam que o critério de reação trata, basicamente, de verificar se as reações ao programa foram favoráveis ou desfavoráveis, positivas ou negativas, convindo lembrar que reações favoráveis não são uma garantia de que ocorreu aprendizagem, nem que o comportamento dos aprendizes foi mudado em virtude de sua exposição ao programa. Não obstante, há várias razões que fazem com que a avaliação de reação seja importante:1) ajuda a assegurar o apoio organizacional para programas dessa natureza; 2) fornece informações que auxiliarão a preparação de futuros programas; 3 ) reações fa- voráveis podem aumentar a motivação do aluno (no caso, o professor) para aprender.

Cada um dos quatro critérios citados acima é amplamente analisado por Kirkpatrick $(1987,1975)$, mas a presente pesquisa se limita apenas ao primeiro.

\section{TV Escola}

O Projeto TV Escola foi concebido para atender à rede de ensino público de São Paulo, com o objetivo de enriquecimento curricular e a capacitação dos professores que integram seus quadros. Foram exibidos 195 programas de $1^{\circ}$ de março até 31 de dezembro do ano de 1994, de segunda a sexta-feira, das $7 \mathrm{~h} 30 \mathrm{~min}$ às $8 \mathrm{~h}$. A CENP organizou o Programa em dois blocos. $\mathrm{O}$ primeiro, com duração de 5 minutos, foi composto por experiências de diferentes práticas pedagógicas desenvolvidas nas escolas, cultura geral, projetos de enriquecimento curricular, atualidades ligadas à educação, pesquisas, divulgação de projetos de capacitação docente e diferentes suportes educativos, e o segundo, com duração de 20 minutos continha informações sobre temas curriculares, com abordagens diferentes e atuais (SEE/CENP/RTC, 1994).O segundo bloco do vídeo da TV Escola era acompanhado de fascículos impressos que continham textos e sugestões de leituras complementares a respeito dos conteúdos tratados.

Visto que o projeto tinha por fim a capacitação dos professores de ensino fundamental do ensino público do Estado e o enriquecimento do seu conhecimento curricular, pensou-se na realização da presente pesquisa com os professores imediatamente após o término do curso, que na verdade foi desenvolvido não por meio de emissões de TV, mas por intermédio de uma série de cópias dos programas emitidos, gravados em VT. Circunscreverse-á esta pesquisa ao aspecto antes salientado: a 
uma avaliação de reação, segundo a terminologia adotada por Kirkpatrick, mencionada anteriormente.

\section{Objetivos}

Foi proposto como objetivo específico a ser analisado por intermédio da presente pesquisa:

- Verificar as reações gerais dos professores ao Projeto TV Escola

\section{Método}

\section{Sujeitos}

Foram sujeitos desta pesquisa 33 professores, sendo 32 do sexo feminino, pertencentes a três escolas públicas estaduais de um município de pequeno porte do Estado de São Paulo, localizado a cerca de $76 \mathrm{~km}$ da capital. Os professores foram selecionados por terem participado de curso de capacitação do projeto TV Escola. Não houve seleção interna para determinar dentro do curso escolhido quais seriam os sujeitos. Todos os que concluíram o curso puderam responder e assim chegou-se ao número pesquisado.

Tabela 1. Caracterização dos sujeitos: distribuição percentual de diferentes variáveis

\begin{tabular}{|c|c|c|c|c|c|c|c|c|}
\hline \multicolumn{2}{|c|}{ Séries } & \multicolumn{2}{c|}{ Disciplinas } & Formação Secundária & \multicolumn{2}{c|}{ Formação } \\
lecionadas & \multicolumn{2}{c|}{ lecionadas } & \multicolumn{2}{c|}{ (magtério) } & \multicolumn{2}{c|}{ Superior } \\
\hline $1^{\mathrm{a}}$ a $4^{\mathrm{a}}$ & $5^{\mathrm{a}}$ a $8^{\mathrm{a}}$ & $\mathrm{SR}^{*}$ & Polivalente & Especifica & Sim & Não & Sim & Não \\
\hline $48,6 \%$ & $36,2 \%$ & $15,2 \%$ & $69,7 \%$ & $30,3 \%$ & $81,7 \%$ & $18,3 \%$ & $60,6 \%$ & $39,4 \%$ \\
\hline
\end{tabular}

*SR $=$ sem resposta

\section{Material}

$\mathrm{O}$ instrumento utilizado foi um questionário maior, preparado pela Autora, para buscar respostas a outros objetivos além do que foi objeto do presente relato de pesquisa. Nesse trabalho utilizaram-se cinco das questões formuladas para a caracterização dos sujeitos e as questões que buscaram uma avaliação de reações sobre a TV Escola.

As questões fechadas foram submetidas a tratamento estatístico por computador, sendo utilizado o programa SPSS for Windows, Versão 5.01 (Outubro 1992). O nível de significância usado na maioria dos casos foi de $5 \%$. A análise das respostas oferecidas às questões abertas foi realizada sob o prisma da análise de conteúdo proposta por Bardin (1977), determinando-se categorias iniciais e globais.

\section{Procedimento}

Foi selecionado o único curso que no período de coleta dos dados correspondia aos critérios exigidos pela CENP para ser considerado um curso de capacitação docente.

Foram aplicados coletivamente questionários impressos, durante a reunião especialmente marcada para esta finalidade, na escola o curso foi realizado.

\section{Resultados e discussão}

Os dados aqui relacionados dizem respeito às reações dos sujeitos ao projeto TV Escola propriamente dito.

Ao avaliarem o potencial de capacitação da TV Escola e de projetos semelhantes (Tabela 2), os sujeitos da presente pesquisa, em sua maioria, forneceram respostas positivas, se bem que apenas $3 \%$ concordaram com a afirmação mais enfática nesse sentido, isto é, "pode, sem dúvida, capacitar o professor". A maioria deles $(69,7 \%)$ considerou que o projeto ajuda a capacitar o professor. 
Verificou-se ainda que, dentre as categorias que obtiveram freqüência, a distribuição não pode ser considerada homogênea $\left(X^{2}=22,55\right.$; gl=2 e $\mathrm{p}<0,001$ ), sendo altamente significantes as diferenças encontradas. As respostas que apresentaram a TV Escola como não suficiente para a capacitação foram mencionadas por cerca de quatro em cada dez sujeitos. Esses sujeitos nos advertem quanto ao problema da concentração de recursos de treinamento ou aperfeiçoamento em uma só modalidade de curso de capacitação. A vasta multiplicidade de aspectos, problemas e desafios que demandam reciclagem e aperfeiçoamento no que tange à atividade docente está a exigir que se recorra a uma gama ampla de técnicas, procedimentos e recursos, entre os quais a TV e o vídeo sem dúvida têm seu lugar, mas não com exclusividade, nem limitados a um só curso.

Tabela 2. Avaliação do potencial da

TV Escola e de projetos semelhantes para a capacitação docente

\begin{tabular}{|l|c|c|}
\hline \multicolumn{1}{|c|}{ Respostas } & F & $\%$ \\
\hline Ajuda a capacitar o professor & 23 & 69,7 \\
Oferece alguma ajuda, mas não é suficiente & 9 & 27,3 \\
Pode, sem dúvida, capacitar o professor & 1 & 3,0 \\
Dificilmente ajuda a capacitar o professor & 0 & 0 \\
Total & 33 & 100 \\
\hline
\end{tabular}

Como demonstra a Tabela 3, os professores foram unânimes em apontar a TV Escola como útil. A distribuição das respostas nas categorias que obtiveram freqüência mostra ser homogênea $\left(X^{2}=2,45 ; \mathrm{gl}=1 \mathrm{e} \mathrm{p}>0,05\right)$. Porém, considerando-se todas as alternativas possíveis de serem escolhidas, pode-se dizer que, diante destas, a distribuição não é homogênea, concentrando-se em duas categorias somente.
Estes números permitem que se afirme com segurança que os sujeitos não têm dúvidas quanto ao grau de utilidade do programa. Todos o consideraram útil, em menor ou maior grau. Não há sequer um sujeito que apresente alguma indecisão nessa avaliação, tampouco aqueles que a viram como totalmente inútil. Isso é muito significativo e indica que, mesmo que se constate uma reação de professores não totalmente favorável à TV Escola, eles conseguem perceber que a mesma tem seus aspectos positivos que a fazem útil para fins de ensino-aprendizagem.

Tabela 3. Avaliação do grau de utilidade específica do projeto TV Escola para a capacitação dos participantes

\begin{tabular}{|l|c|c|}
\hline \multicolumn{1}{|c|}{ Respostas } & F & $\%$ \\
\hline Útil & 21 & 63,6 \\
Muito útil & 12 & 36,4 \\
Total & 33 & 100 \\
\hline
\end{tabular}

Verificar as reações dos professores à TV Escola pode contribuir para um melhor aproveitamento de projetos futuros. Quando se constata a intenção dos Governos Estadual e Federal em implementar em grande escala a capacitação docente por meio de TV/VT como vem ocorrendo, é alentador um dado como o de que professores que passaram por uma capacitação com essas características reconheceram sua utilidade e que ela talvez sirva para colaborar na obtenção de bons resultados no futuro.

Reforçando os indícios das reações dos sujeitos à TV Escola, referidos anteriormente, os professores foram $100 \%$ concordes em afirmar que a consideraram interessante. Ao avaliar o projeto como interessante, infere-se que provavelmente houve uma aceitação dos ganhos que poderiam advir do mesmo e/ou de sua construção. Não se afirma categoricamente que 
um projeto para capacitação docente com as características da TV Escola é interessante em virtude de um julgamento superficial a este respeito.

$\mathrm{Na}$ Tabela 4, os professores apresentam a avaliação que fizeram da aprendizagem obtida por meio da TV Escola. Mais uma vez, eles se concentraram em respostas positivas. Não houve sequer um sujeito que julgou não ter aprendido nada, muito pouco ou pouco com o projeto. A distribuição das respostas na categorias que obtiveram freqüência é homogênea $\left(X^{2}=0,03 ; \mathrm{gl}=1\right.$ e $\left.\mathrm{p}>0,05\right)$. Em relação a todas as categorias, é lícito afirmar que o professor da presente pesquisa julgou que aprendeu algo com a TV Escola. Isto é bastante animador, uma vez que, respondendo que aprendeu, o sujeito permite inferir que o projeto é capaz de ensinar, apresentando-se, portanto, como um meio que pode proporcionar uma melhoria dos conhecimentos do professor.

Tabela 4. Auto-avaliação de aprendizagem por meio do projeto TV Escola

\begin{tabular}{|l|c|c|}
\hline \multicolumn{1}{|c|}{ Respostas } & F & $\%$ \\
\hline Aprendi razoavelmente & 17 & 51,5 \\
Aprendi bastante & 16 & 48,5 \\
Total & 33 & 100 \\
\hline
\end{tabular}

Quando inquiridos se os objetivos do projeto estavam sendo alcançados, a maioria dos sujeitos respondeu afirmativamente (97\%). Ao afirmarem que os objetivos estavam sendo atingidos, infere-se que os sujeitos consideraram todo o contexto da capacitação para emitir essa resposta, desde as condições estruturais até a avaliação de sua aprendizagem. Aqui se constata uma coerência do sujeito, pois anteriormente ele afirmou que aprendeu e agora julga que os objetivos propostos pela TV Escola estão sendo cumpridos, considerando-se que o objetivo maior do projeto o de proporcionar um ganho de aprendizagem capaz de melhorar a prática docente e contribuir para a melhoria dos índices educacionais no Estado. Com essas afirmações, pode-se supor que o professor acredita que melhorou seus conhecimentos ao freqüentar o curso e que estes poderão ajudá-lo na prática em sala de aula. Mas como foi dito anteriormente, apenas uma pesquisa específica nesse sentido poderá comprovar essas suposições.

Ao serem inquiridos sobre o que mais sentiram falta na TV Escola, os professores apresentaram argumentos que foram classificados em quatro categorias globais de análise (Tabela 5). A que obteve maior freqüência referiuse a problemas com os conteúdos (48,6\%). Para caracterizar esses problemas, foram oferecidas indicações a respeito da falta de prática $(28,6 \%)$ nos vídeos. Ou seja, parece haver uma indicação de que os professores desejavam ver na TV Escola modelos de ação que pudessem ser diretamente aplicados em sala de aula. Em seguida, com 11,4\% das argumentações, foi apontada a falta de conteúdos programáticos nos vídeos. $\mathrm{A}$ inadaptação à realidade dos vídeos obteve $5,7 \%$ do total de argumentos. Isto parece indicar que o grupo de professores gostaria de ver nos programas salas de aula lotadas, falta de condições materiais e outras situações comuns no dia-a-dia da escola pública, para considerar que o vídeo é completo e pode ensinar algo. Essa dúvida merece ser mais bem pesquisada. Talvez exista aqui algum indício de como as pessoas retiram informações e obtêm conhecimentos a partir de um produto audiovisual. Por fim, com $2,9 \%$ de argumentos, o grupo sentiu falta de informações sobre a resolução de problemas freqüentes em sala de aula. Estes problemas são relacionados a aspectos como disciplina e desinteresse dos alunos, por exemplo. Essa indicação pode significar que os pro- 
fessores não têm sido preparados suficientemente bem em seus cursos para lidar com tais problemas. Segundo Britto (1994), a formação docente é falha e não acompanha as modificações da sociedade e as novas exigências da escola.

Tabela 5. O que o grupo de professores mais sentiu falta na TV Escola

\begin{tabular}{|c|c|c|}
\hline Categorias encontradas & $\mathbf{F}$ & $\%$ \\
\hline \multicolumn{3}{|l|}{ 1. Problemas com os conteúdos } \\
\hline A. Falta de prática & 10 & 28,6 \\
\hline B. Conteúdos programáticos & 4 & 11,4 \\
\hline C. Inadaptação à realidade & 2 & 5,7 \\
\hline D. Resolvendo problemas & 1 & 2,9 \\
\hline Subtotal & 17 & 48,6 \\
\hline \multicolumn{3}{|l|}{ 2. Problemas técnicos/burocráticos } \\
\hline A. Qualidade técnica & 5 & 14,3 \\
\hline B. Infra-estrutura & 4 & 11,4 \\
\hline Subtotal & 9 & 25,7 \\
\hline \multicolumn{3}{|l|}{ 3. Falhas no planejamento dessa capacitação } \\
\hline A. Pessoal qualificado em treinamento & 2 & 5,7 \\
\hline B. Estratégias da capacitação & 2 & 5,7 \\
\hline C. Visão geral & 1 & 2,9 \\
\hline Subtotal & 5 & 14,3 \\
\hline \multicolumn{3}{|l|}{ 4. Sem problemas } \\
\hline Avaliação positiva & 4 & 11,4 \\
\hline Subtotal & 4 & 11,4 \\
\hline Total de argumentos & 35 & 100 \\
\hline
\end{tabular}

Na segunda categoria global de análise, $\operatorname{com} 25,7 \%$ de frequiência, houve a apresentação de problemas técnicos/burocráticos na TV Escola. Esses problemas foram relacionados com a qualidade técnica dos vídeos (14,3\%), principalmente de som e imagem, e com a infraestrutura do projeto (11,4\%), que não se encar- regou de providenciar todo o material necessário para o curso, sendo preciso despender tempo e dinheiro para conseguir aquilo que deveria ter sido facilmente introduzido no curso.

Falhas no planejamento dessa capacitação foram apontadas em 14,3\% dos argumentos apresentados como um aspecto que merece ser criticado. Foram consideradas falhas a falta de pessoal qualificado para treinamento $(5,7 \%)$ e a falta de estratégias específicas de capacitação $(5,7 \%)$. Essas duas categorias iniciais estão diretamente relacionadas. Foi constatado que uma pessoa não preparada para dirigir um curso específico de capacitação, mais específico ainda por ter como principal recurso o vídeo, responsabilizou-se pelo mesmo e provavelmente não estava apta a desenvolver estratégias eficazes de aprendizagem. A última falha apontada pelo conjunto foi a falta de visão geral dos vídeos (2,9\%). Entretanto, aqui, não se pode concordar com essa argumentação, uma vez que num curso de 30 horas seria impossível passar em revista todo o conjunto de vídeos produzidos para a TV Escola, nem deve ser esse o objetivo. Afinal, espera-se que um curso seja planejado para atingir determinados objetivos e para isso sejam selecionados os vídeos que mais se adaptem a estes.

Foi ressaltado antes que, em quase todas as respostas às questões, os sujeitos destacaram mais o aspecto positivo da TV Escola, e isto não poderia faltar aqui. Do total de argumentos, $11,4 \%$ afirmaram não haver problemas com o projeto, fazendo, assim, uma avaliação positiva deste.

\section{Conclusão}

Este trabalho relatou os resultados de uma pesquisa sobre as reações de professores do ensino fundamental à utilização de um projeto desenvolvido com o propósito de proporcionar capacitação docente: a TV Escola.

Reações positivas foram encontradas quanto ao projeto TV Escola com o meio de ca- 
pacitação docente. No entanto, foi igualmente ressaltada pelos sujeitos a insuficiência desse recurso. Há uma sugestão de que outros recursos de capacitação e um maior número de cursos sejam oferecidos. Para os sujeitos, o aspecto de maior benefício está associado ao fato de a TV Escola ter sido estruturada sob a forma de ensino à distância.

A presente pesquisa está longe de abranger a infinidade de aspectos compreendidos no emprego de televisão e vídeo a serviço de objetivos educacionais num sentido amplo e, mesmo no sentido específico, voltado para a reciclagem de docentes. No entanto, fornece subsídios úteis para projetos em andamento e futuros.

As reações a curto prazo de um grupo seleto de professores submetidos a um curso de educação à distância são inegavelmente de alcance limitado e precisam evidentemente ser corroboradas (ou não) por outras investigações, com grupos distintos de docentes. Sugerem igualmente a necessidade de que tanto os pesquisadores como os responsáveis por projetos similares de educação à distância considerem aspectos como a especificação mais precisa, operacional, de objetivos que visam o ensinoaprendizagem (algo que aparentemente não ocorreu no projeto TV Escola), o planejamento e a produção dos materiais de ensino (programas de TV/VT, impressos e outros).

É igualmente imperioso que iniciativas como a da TV Escola sejam, desde a sua concepção, solidamente embasadas numa preocupação de pesquisa e avaliação, se o que se pretende é obter resultados que traduzem melhoria de fato nos sujeitos a que se destinam essas iniciativas.

\section{Referências}

Bardin, L. (1977). Análise de conteúdo. Tradução de Luís Antero Reto e Augusto Pinheiro. São Paulo: Edições 70.

Britto, M.S. (1994). Magistério em tela: dificuldades na atuação e formação do professor de $1^{\circ}$ Grau. Dissertação de Mestrado. Campinas: PUCCAMP.

Funtevê. (1984). Qualificação Profissional. Rio de Janeiro: Ministério da Educação e Cultura.

Fusari, J.C. (1988). A educação do educador em serviço: o treinamento do professor em questão. Dissertação de Mestrado. São Paulo: PUC.

Gait, N. (1988). Teleducação em São Paulo: Passado e Futuro $o_{\star}$ Tese de Doutorado. São Paulo: USP.

Guzzo, R.S.L. (1985). Refletir para mudar ou apenas para constatar as dificuldades? Um desabafo daqueles que alfabetizam. Estudos de Psicologia, $\mathrm{n}^{\mathrm{s}} 2$ e 3, agosto/dezembro, pp. 149-157.

IBGE. (1994). Censo Demográfico do Brasil de 1991. Rio de Janeiro: IBGE.

Jegede, O.J. (1994). Distance education research priorities for Australia: A study of the opinions of distance educators and practitioners. Distance Education, vol. $15, \mathrm{n}^{\circ} 2$, pp. 234-253.

Kirkpatrick, D.L., ed. (1975). Evaluating training programs. Alexandria: American Society for Training and Development.

Kirkpatrick, D.L. (1987). Evaluation of training. In Craig, R. L. (ed.) Training and development handbook. New York: MacGraw-Hill.

Rezende e Fusari, M.F. (1990). Meios de Comunicação na Formação de Professores: televisão e vídeo em questão. Tese de Doutorado. São Paulo: USP.

SEE/CENP-RTC. (1994). Ensino à distância: TV ESCOLA. (Relatório do projeto TV ESCOLA).

Wexley, K.N. e Latham, G.P. (1991). Developing and training human resources in organizations. New York: HarperCollins. 